\title{
'|||||||||||||||||||||||||||||||||||||||||||||||||||||||||||||||||||.
}

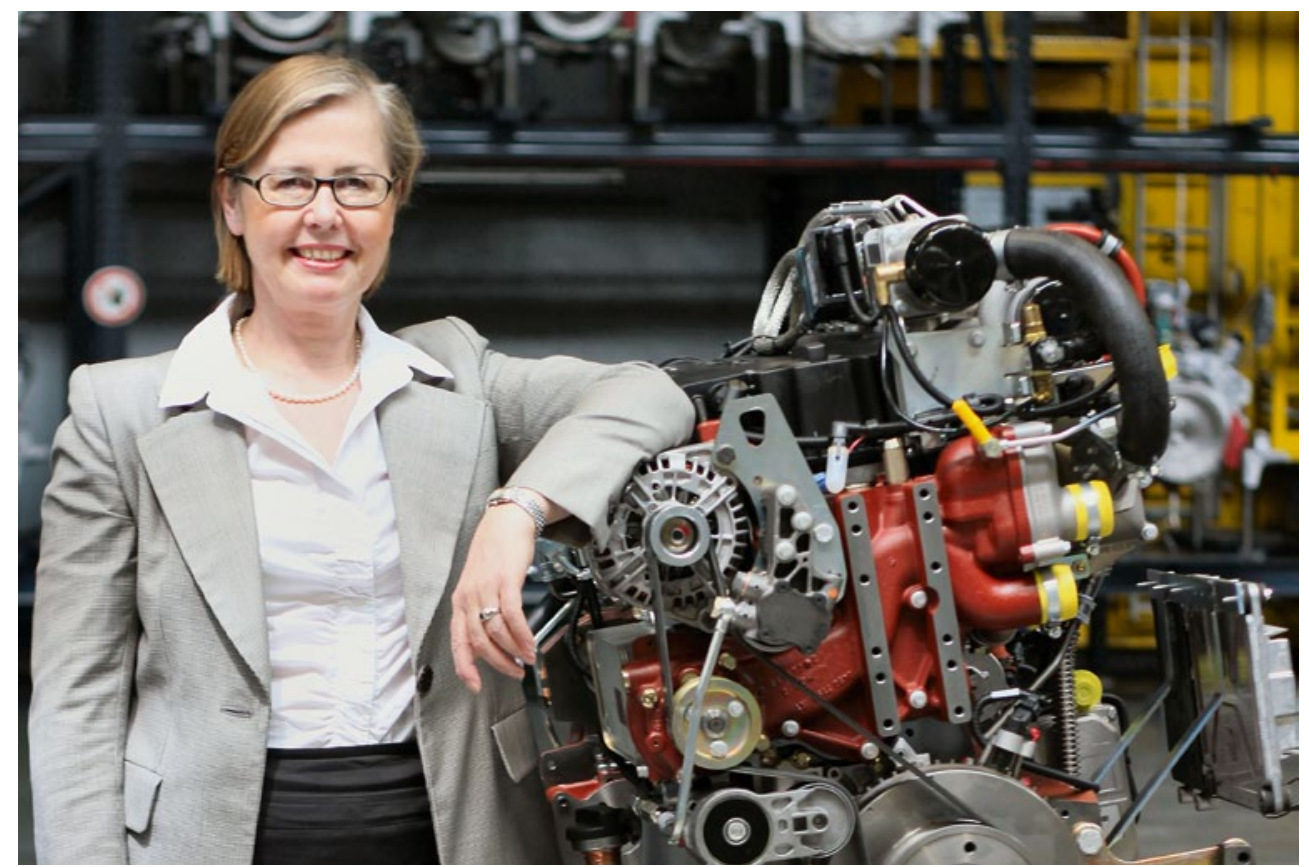

DR. MARGARETE HAASE

Mitglied des Vorstands der Deutz AG

\section{MIT DIESELMOTOREN GELD VERDIENEN}

Der Trend zum Outsourcen von Motorenentwicklung und Motorenproduktion führt zu mehr Kostentransparenz. Während Komponenten und Teile in der Automobilindustrie überwiegend von Zulieferern stammen und durch kontinuierliche Wettbewerbsvergleiche hohe Kostentransparenz aufweisen, sind Motoren beim OEM in der Eigenfertigung weniger dem Wettbewerbsdruck ausgesetzt. Zwar werden Zielkosten vom Wettbewerb abgeleitet, die Transparenz der Wettbewerbskosten ist jedoch deutlich geringer als im hoch standardisierten Zuliefergeschäft.

In der politischen Debatte steht beispielsweise das Trendthema Elektromobilität im Vordergrund. Die Diskussion um die Frage, was den Absatz dieses Produkts bis heute auf eine verschwindend geringe Basis drückt, löst hohe Entwicklungskosten für unterschiedlichste Antriebstechnologien aus, deren Rentabilität schwer vorherzusagen ist.

Um aber auf Dauer wettbewerbsfähig zu bleiben, muss das Gesamtfahrzeug die Kosten hereinspielen. Dies erhöht den Druck auf die Komponentenzulieferer. Der Antrieb als „Motor“ einer wettbewerbsdifferenzierenden Technologie wird als werttreibend zur Stärkung der Marktposition begriffen. Vor diesem Hintergrund kann Outsourcing von Motoren der Schlüssel zu höherer Wettbewerbsfähigkeit sein. Wird im Baumaschinenund Landmaschinensektor die Motorenproduktion wegen der Skaleneffekte häufiger zu unabhängigen Herstellern verlagert, ist dies in der Automobilbranche weniger ausgeprägt. Da durch Outsourcing mehr Transparenz, mehr Wettbewerb und höherer
Kostendruck entsteht, kann die Verlagerung der Motoren nach außen weitere Kostensenkungspotenziale eröffnen.

Unabhängige Motorenhersteller, wie zum Beispiel Deutz, verdienen Geld allein mit dem Motor und sind es gewohnt, frühzeitig Richtungsentscheidungen für Technologien zu treffen, da Fehlinvestitionen und nicht zielführende Vorentwicklungen meist vom Kunden nicht bezahlt werden. Dabei steht ein reiner Motorenhersteller stärker als ein OEM unter dem Druck, Komplexität zu vermeiden, um Skaleneffekte zu heben, denn weniger komplexe Produkte gewährleisten schlankere Strukturen und Prozesse. Zusätzlich bedingen die knapperen Mittel, mit einer definierten Technologie möglichst hohe Volumina zu bewegen.

Im Vergleich mit dem OEM beschäftigen sich Motorenentwickler im Non-Captive-Segment deutlich intensiver mit Fragen wie: Bezahlt der Kunde für meine Entwicklung? Sind Weiterentwicklungen mehrpreisfähig? Ist es innerhalb der Produktion möglich, meine Produktentwicklung in kostengünstige Prozesse zu transformieren? Ist das Motorendesign geeignet, möglichst viele Anwendungen zu bedienen? Wie kann ich die Teilevielfalt minimieren, ohne dem Kunden das Gefühl zu geben, er bekommt einen Motor „aus dem Regal“?

Trotz ausgeprägtem Kostenbewusstsein und Umweltschutz muss auch im B2B-Geschäft ein Motor faszinieren können. Aufgrund dieser Balance zwischen Wirtschaftlichkeit, Umweltbewusstsein und Leidenschaft für Innovation führt der Weg ins Jahr 2014 nicht am Dieselmotor vorbei. 